\title{
Vigília das oralidades
}

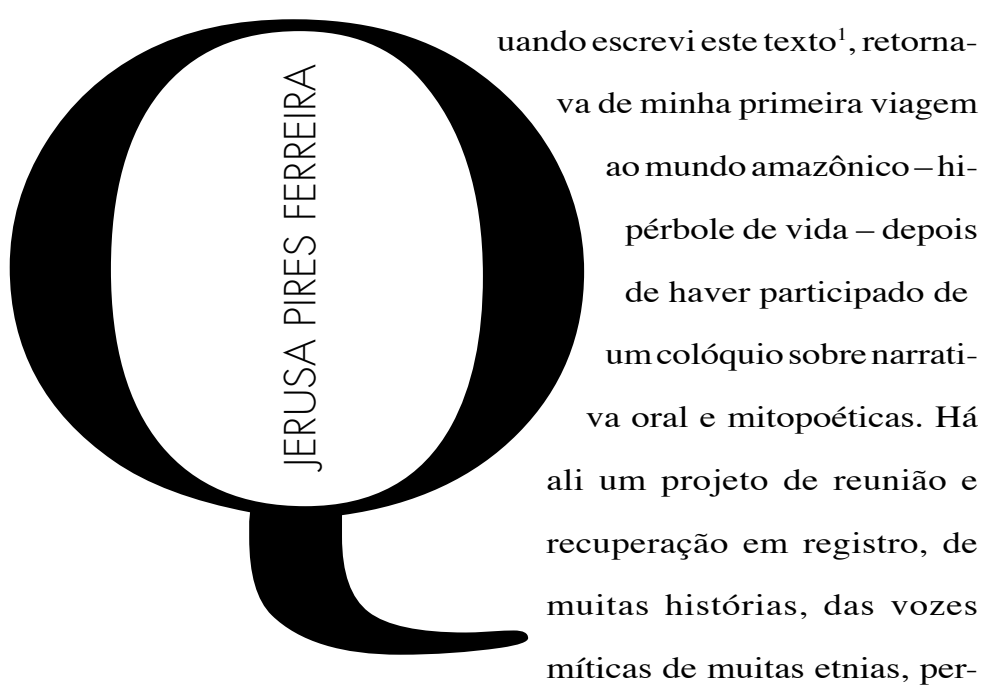

meadas pela dicção da cultura luso-brasileira, assentadas nos vários registros dos gêneros da literatura tradicional oral, de procedência ibérica. Encontrase escondida, na selva inacessível, a voz de povos indígenas, de tantos idiomas que se oferecem, em desafio, aos antropólogos, lingüistas, semioticistas.

A dimensão insuspeitável desse cosmo nos oferece da Memória (Ateliê). uma antevisão da complexidade do que é pensar tradição, voz, oralidade, em nosso continente. Tudo nos convida a situar o diálogo de culturas, de práticas e ritos e alcançar também as possibilidades e as ações de extermínio, a intensidade de conflitos que comprometem dominadores e povos nativos, desde sempre. Seria indispensável, por isso, não perder de vista o que representam essas vozes, expressões primordiais que se articulam entre construções milenares de formas de viver e de representar o cosmo, de organizar em vivência tudo o que a elas se sobrepõe. 
Em seu livro Introduction à la Poésie Orale $^{2}$ comenta Paul Zumthor, depois de extensa observação em vários continentes, inclusive ao Brasil, o desastre de tantas vozes silenciadas, de tantos idiomas extintos. Constata o silêncio que pesa sobre nós, quando se cala um imenso saber, uma sabedoria, a fidelidade à vida. Continua pontuando que a destruição de culturas veneráveis vitima a humanidade inteira, privada de seu trabalho milenar, de sua memória e de seus mortos.

Falar de tudo isso é colocar em cena um escritor como Augusto Roa Bastos. Situar essa problemática é avançar no cerne de suas preocupações, não só em sua obra posterior, mas em seu universo ficcional.

Devo dizer que, em que pesem os esforços isolados, a obra do grande escritor paraguaio não é facilmente disponível nas livrarias brasileiras. Fenômeno como esse nos faz pensar que a América Latina é um frágil conceito e que muitas barreiras se contrapõem à circulação e presença de nossos escritores.

Em 1994, pelas mãos de um estudante paraguaio, Miguel Angel Correa, tive acesso a La Vigilia del Almirante ${ }^{3}$ na Bahia, minha região natal. Confesso que um encanto profundo se instalou em meu espaço vital, e poderia dizer que me encontrei situada em um desafio de presença e ausência, marcando em poéticas de tempo/espaço a insistência dos mitos, no sentido original de narrativa primeva. Então me propus a seguir o diálogo do autor com o texto bíblico, a força intertextual do Livro de Jó, transpostas outras paragens, a presença cervantina e o Quixote retomado em tantas seqüências. Foi possível acompanhar, nas dobraduras da construção histórica, a ficção em escrituras superpostas, em que uma outra história se insurge. Assim, a própria dinâmica das teorias do texto, da cultura, da escritura, urdida nesse conjunto aliciante. Pode-se ver, então, como o escritor paraguaio prossegue na operação de dar voz aos fantasmas, de escutar vozes que não foram escritas, propondo-se quase a uma arqueologia de vozes soterradas, fabricação de alegorias, a partir de eixos míticos, de histórias documentadas ou não, escrituras que se superpõem em palimpsestos. Por essa razão, escrevi a Paul Zumthor sobre a experiência de leitura tão intensa, e ele me respondeu, manifestando quanto lhe parecia urgente se aproximar de Roa e de seu mundo viajante. Justo ele que havia escrito um livro sobre Colombo e sua aventura, La Traversée 4 , e que, naquela ocasião, preparava um grande trabalho sobre voz, espaço e memória - La Mesure du $M_{o n d} e^{5}$, no qual aproximava as noções de lugar e movimento para um desconhecido desejável, como no caso das utopias ou dos descobrimentos, em que se mesclam valores sensoriais e simbólicos. Nada nos parece mais oportuno para pensar um texto como La Vigilia del Almirante.

\section{LA VIGILIA}

Podemos dizer que nesse livro a grande metáfora é a de uma viagem paralisada por um mar de sargaços, impossibilidade de deslocamento que agoniza todos os sentidos. Prisão transcendente. Paradeiro. Seria fácil transpor, para o fato da paralisação, a cristalização perene do escrito, frente à infinita multiplicidade do oral, como força propulsora. Tudo nos convida a pensar adiante, na voz "tutorial", paralisante como esse mar de sargaços, definida no Yo el Supremo ${ }^{6}$ como a encarnação do poder e do arbítrio: "el poder de la escritura solo existe cuando és escritura del poder", nos confirma o novelista. Situado entre a cultura guarani ${ }^{7}$, entre interdição e desafio, e a espanhola, expressa pelo castelhano, representando os pretensos avanços de civilização, o autor se volta inexoravelmente para as culturas condenadas, buscando vozes e lendas, sopros e cantos. Está atento para perceber, intensamente, tudo o que foi reprimido ou recalcado, observando o suporte silencioso de tantas escrituras que ganhariam foros de poder. Mas as oralidades estariam, em vigília, despertas para a possibilidade de reverter o escrito, de realizar uma sabotagem a ele, de criar um respiro no cimento fresco, conforme imagem de Paul Zumthor 
na conclusão de um de seus livros. Sabemos, por várias fontes ${ }^{8}$, que para escrever Yo el Supremo o escritor investigou a vida de dr. Francia e a história do Paraguai durante vinte anos, alcançando a gravação de milhares de horas de fita-cassete, buscando o fundo das tradições orais e denominando-se compilador, como faziam os autores de novelas de cavalaria. Fantasia ou verdade, que importa - se o que conta é sobretudo a atitude? O significado de número tão impressionante vale, sobretudo, pela busca e instalação de muitas vozes que nos remetem à possibilidade antiautoritária, à inacreditável arquitetura polifônica - que vai do universo indígena ao grande "concerto barroco". Por isso, disse Roa Bastos - em entrevista e ao comentar sua nova novela Madame $S u{ }^{9}$, em que fala na pele de sua personagem, uma mulher (a amante do general Stroessner) -, que na palavra escrita se perde a vibração natural da palavra oral, própria da cultura paraguaia, em sua origem e desenvolvimento. Deveríamos pontuar dizendo que uma tal formulação acompanha sua posição extremada, relacionada ao oral, que considera como força de vida, enquanto o escrito seria congelamento e opressão.

É oportuno comentar que escrita e oralidade se interseccionam com freqüência e que uma está impregnada de outra. Por isso, La Vigilia freqüenta esse paradoxo. Para ser construída, utiliza ecos de vozes e memória visual que se alimenta de imagens e de signos impressos. Opõem-se o coletivo - domínio da comunicação oral -e o individual - em que se ancora o escrito. Ao exagerar situações, ele nos fornece os índices do impasse, e tenta o emergir desse conjunto de signos no qual se defrontam o alfabeto e a escritura com as forças vitais, para que se possa sair desse mar de sargaços. Não há sistema de signos que possa responder pela multímoda fluência da vida. Não há mediação que possa dar conta da voz em presença, das conjunções e ressonâncias, em que se ligam os corpos em comunicações vivas e ritualizantes, ainda que possam inaugurar outras instâncias da comunicação e da criação. Mas é claro que A Vigília da Oralidade consiste na articu- lação onipresente da voz. Desde o diário do capitão (escrito) que se conta e articula ao confronto de vozes vivas em presença. Ao seguir viagem, o Almirante, ao superar o impedimento de algas pútridas, nos leva ao encontro da "voz de todos os tempos", permissão para viajar entre a "voz judia", "a voz indígena", vozes concretas ou visionárias, conforme o caso, e que vão tecendo um grande texto, suporte indispensável para que se pense toda uma cultura. Esse texto se compõe de urdiduras antagônicas (voz é também palavra).

O herói, Colombo-Jó, viaja sob a nuvem carregada da Inquisição e, como uma persistente ameaça, persegue-o a voz tutorial. Quando o autor dá vez àqueles que de mitos passam a "exterminados", a escritura vai recuperando os arcaísmos, através de acentos e sinais que fazem uma mescla de texto oral/escrito.

Roa compartilha a idéia de Meliá de que, quanto à conquista, primeiro se dá a do território, mas seu último e definitivo passo $^{10}$ é quando o idioma de um povo já tenha sido também ocupado ${ }^{11}$. Empenhase em uma espécie de ação desocupadora: “[...] la palabra viva dice siempre la verdad, aunque no lo diga... vuela libre. La letra se ha hecho para mentir", conclui.

\section{A VOZ, SUAS EXTENSÕES, POR UMA VOCIGRAFIA}

Nessa novela, que se traga a si mesma, estão em causa muitas e diferentes vozes, como as da profecia, do vaticínio, projeções do passado ao futuro, delineando signos de tragédia. Assim podemos atentar para a escuta "con oídos muertos, las personas de los primeros tiempos empiezan a escuchar por la piel". A sabedoria é então vista como memória da experiência humana, pairando, a memória, como oralidade emergente e virtual. A escritura é sempre traidora, razão que faz com que encontremos o Almirante lendo em voz alta, seguindo as pausas da escrita e do diário de bordo. Há, nesse pon-
8 Dario Henao Restrepo, El Faús tico en la Nueva Literaria Latino Americana, Leviatã 1992

9 "Roa Bastos Escreve na Pele de uma Mulher", entrevista de Roo Bastos ao Estado de S. Paulo, $2 / 3 / 96$

10 Introdução de Las Culturas Condenadas, op. cit

11 "El que Hace Escuchar la Palavra, por Bartolomeu Meliá in Las Culturas Condenadas, op. cit. 
to, como em outros da obra de Roa Bastos, uma obsessão pela memória, pela captação dos repertórios, pelo encontro dos suportes iniciais, base da comunicação viva. Chega ao ponto de dizer que não podemos nos comunicar, senão sobre este solo arcaico. Por isso, evoca as construções fabulosas, o lago de águas esmeraldinas, os rios centrais do paraíso, em sequiências captadas a partir do conto maravilhoso.

Busca então a criação vocabular, o giro das palavras, que nos remetem às sonoridades: "indumentaria de velas, velos, desvelos". Organiza lutas de palavras e verdadeiras liturgias que cercam a emissão da voz: desvela/revela ou avança em invenção de palavras como linguaraz, falando sobre o mal-entendido ou sobre a querela adâmica.

Conclui que, entre ele e o mundo, só existe um mal-entendido e que a descoberta de um mundo desconhecido vai resultar naturalmente em outras vozes.

Em La Lettre et la Voix ${ }^{12}$ nos diz Paul Zumthor que deveríamos pensar em uma nova ciência que se ocupasse de uma espécie de vocigrafia, de modo a perceber as unidades de voz, os vocemas (em seguida se repreende pela nomenclatura). Ele nos chama a atenção, na verdade, para a riqueza das variações vocais, contida no escrito, ou nas vozes que se podem escutar através. Parece que Roa se mantém, como escritor, consciente de toda essa variedade e, por isso, organiza uma diversidade inumerável de realizações vocais. Atenta para o silêncio, para suas pausas e imobilidade, para as palavras roubadas: "escribo palabras". Distingue e revela "las voces de agonia y muerte", como ao utilizar os procedimentos de decifração e ambigüidade, hermenêutica da cabala. Monologa em altas vozes, transmite o conhecimento bíblico, passeia na voz da oração e poesia. Não lhe escapam o tom e a dimensão do timbre, distinguindo a voz próxima, a distante, como entre as "resonancias de un aqueduto". Do mesmo modo que nos apresenta a voz do grito de pavor, encarrega-se de distinguir a "voz tonante", que evoca as entonações do púlpito, tão caras ao discurso religioso do colonizador, e que se transformaria em temor e fascínio para nossos povos. Opõe a voz murmurante.

Creio que é inevitável a comparação de certos fragmentos de Roa com a pulsante composição das Galáxias de Haroldo de Campos - em comum estão a viagem, o livro, o dito, a ressonância em criação fulgurante.

\section{A VOZ DOS LIVROS}

Entre o que se conta e o que se lê, não nos será difícil perceber a força construtiva daquilo que podemos chamar de livros de fundação, responsáveis pelos assentamentos do imaginário popular. As escrituras ${ }^{13}$ se concentram no diário de bordo, no diário do descobrimento, nos livros de casas estranhas. A enumeração e a nominação dos objetos conferem toda uma atenção à escritura que "esconde por transparencia suya olvidos reales o deliberados". Alguém pode pensar que o capitão escreve para que seja lido. Estão enfocados os titubeios literários do capitão, os pastiches ou o falso brilho de miniaturas arábicas, calcadas nas Noches, $\mathrm{e}$ ao compor textos sobre os mortos e sobre a palavra roubada, retiradas de leituras de Luciano de Samósata e de seu Diálogo de los Muertos. São também indispensáveis $E l$ Manual del Perfecto Inquisidor (o famoso manual persecutório de Nicolás Eimerich), os Amadises e Palmerins. Desse repertório, ergue-se um tempo/espaço visionário para a construção do cronotopo da aventura, da descoberta (para usar conceitos de Bakhtin).

\section{$\bullet \bullet$}

E no final do livro chamamos por uma voz que acreditáramos escutar, quando da morte do Almirante - seja de Colombo, de Jó ou do Quixote. Entram a ama e a sobrinha que, soluçando em uníssono, dizem: “Ya no está mas aqui". Voz de réquiem, de condenção, palavra anunciada que nos leva à morte e ao martírio de Cristo - incrível fusão. 

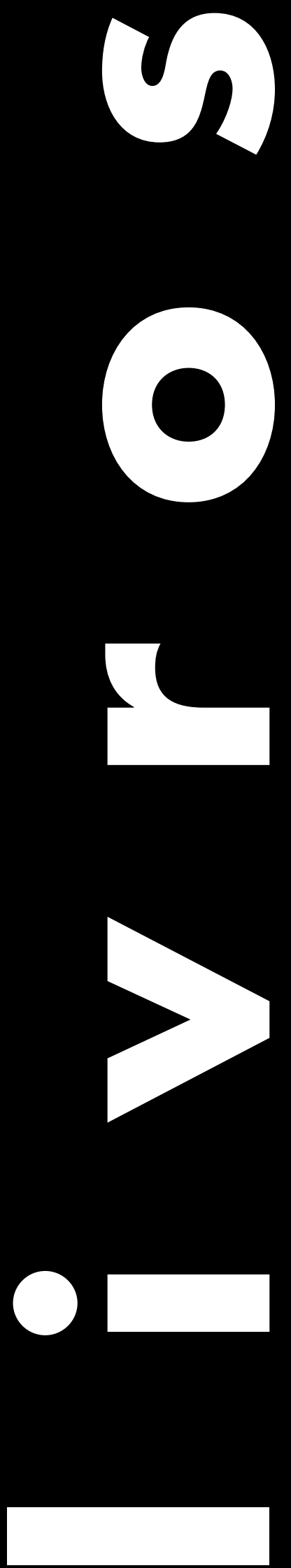